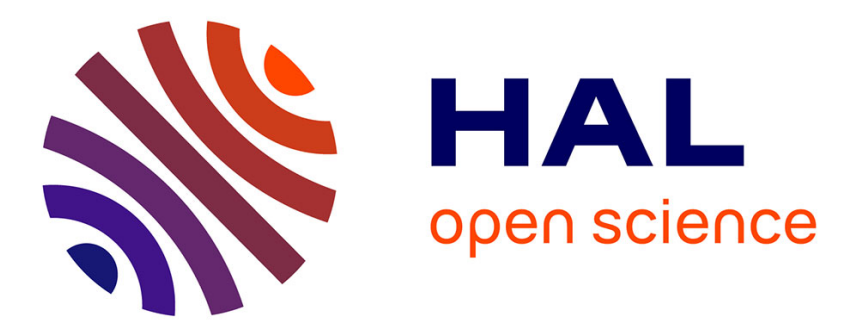

\title{
On the stability of antimony doped tin oxide supports in proton exchange membrane fuel cell and water electrolysers
}

Ignacio Jiménez-Morales, Sara Cavaliere, Marc Dupont, Deborah Jones, Jacques Roziere

\section{To cite this version:}

Ignacio Jiménez-Morales, Sara Cavaliere, Marc Dupont, Deborah Jones, Jacques Roziere. On the stability of antimony doped tin oxide supports in proton exchange membrane fuel cell and water electrolysers. Sustainable Energy \& Fuels, 2019, 3 (6), pp.1526-1535. 10.1039/C8SE00619A . hal02145975

\section{HAL Id: hal-02145975 \\ https://hal.science/hal-02145975}

Submitted on 6 Jan 2021

HAL is a multi-disciplinary open access archive for the deposit and dissemination of scientific research documents, whether they are published or not. The documents may come from teaching and research institutions in France or abroad, or from public or private research centers.
L'archive ouverte pluridisciplinaire HAL, est destinée au dépôt et à la diffusion de documents scientifiques de niveau recherche, publiés ou non, émanant des établissements d'enseignement et de recherche français ou étrangers, des laboratoires publics ou privés. 


\title{
On the Stability of Antimony Doped Tin Oxide Supports in Proton Exchange Membrane Fuel Cell and Water Electrolysers
}

\author{
Ignacio Jiménez-Morales, ${ }^{a}$ Sara Cavaliere, ${ }^{* a}$ Marc Dupont, ${ }^{a}$ Deborah Jones, ${ }^{\text {a Jacques Rozière }}{ }^{a}$ \\ The electrocatalyst support antimony doped tin oxide (ATO) was investigated at low and high potentials with ex situ and in situ electrochemical techniques to \\ assess its stability in proton exchange membrane fuel cell (PEMFC) and water electrolysis (PEMWE) operating conditions.
}

\section{Introduction}

Tin oxide is a support for electrocatalysts with application in proton exchange membrane fuel cells (PEMFC) ${ }^{1-3}$ and water electrolysers (PEMWE), ${ }^{4-6}$ combining high corrosion resistance ${ }^{7,8}$ with strong interaction with metals, that can lead to promoted electrocatalytic effects.9,10 Several doping agents have been used to increase the intrinsic low electrical conductivity of semiconductor $\mathrm{SnO}_{2}$, including niobium, ${ }^{11-13}$ antimony ${ }^{14-16}$, aluminium ${ }^{17}$ and tantalum, ${ }^{18}$ to ensure minimal Ohmic resistance in the targeted energy conversion and storage devices. Tin oxide based nanomaterials with various morphologies (aerogels, nano/microparticles, fibres, tubes) have been synthesised and employed as supports for platinum nanoparticles for the oxygen reduction reaction (ORR) taking place at PEMFC cathodes. ${ }^{8,9,19,20}$ In particular, the great stability of such electrocatalysts over prolonged cycling to potentials up to $1.5 \mathrm{~V} / \mathrm{RHE}$ was highlighted as being the main advantage over conventional carbon-based electrode materials. Whereas most previous work has focused on ex situ electrochemical characterisation, some results obtained on membrane electrode assemblies (MEAs) in single fuel cell characterisation were also reported,, 12 all of them demonstrating the excellent corrosion resistance of $\mathrm{SnO}_{2}$-based cathodes and the overall cathode stability up to $1.5 \mathrm{~V}$. We have earlier described the development and electrochemical characterisation of platinum decorated niobium and antimony doped $\mathrm{SnO}_{2}$ (NTO and ATO, respectively) electrospun loose-tubes as cathode electrocatalysts. High morphological, structural and electrochemical stability of the tin oxide electrodes was demonstrated, ${ }^{21,22}$ which opens up the opportunity for application in PEMWE anodes where high potential is experienced. ${ }^{6}$

While the stability of ATO at the high voltage limits expected for a PEMFC is now accepted, its stability on excursions to lower potentials in an operating fuel cell, where reduction to lower oxidation states $\left(\mathrm{Sn}, \mathrm{Sn}^{2+}, \mathrm{Sb}^{3+}\right)$ of the constituent metal ions can occur, have not been investigated in situ. The possible application of ATO in devices experiencing higher voltage than PEMFC cathodes, such as PEMWE anodes also opens questions on its stability at potentials greater than $1.5 \mathrm{~V} / \mathrm{RHE}$.

We describe here the results obtained when applying an accelerated stress test (AST) comprising on/off and load cycling. This protocol is not dissimilar to that detailed in the "EU Harmonised Test Protocols for PEMFC MEA Testing in Single Cell Configuration for Automotive Applications" of the Fuel Cells and Hydrogen Joint Undertaking (FCHJU), ${ }^{23}$ apposite for Pt/C catalysts, and applied here to MEAs comprising cathode layers of ATO supported platinum. The aim of this test is to stress the fuel cell by means of instantaneous and alternating phases of on and off loads causing frequent changes in pressure and temperature. Furthermore, by sweeping the lower potentials where polarisation is significant (corresponding to $1,5 \mathrm{~A} \mathrm{~cm}^{-2}$ load), this protocol submits the cathode catalyst support to different voltage regimes $(\leq 0.5 \mathrm{~V})$ from the previously investigated cycling to high potentials. The anode and cathode exhaust water was collected and analysed by ICP-MS to determine the origin of any structural instability. Other probe spectroscopic methods including X-ray photoelectron spectroscopy, ${ }^{119}$ Sn Mössbauer spectroscopy, energy dispersive X-ray spectroscopy were employed to characterise the support evolution upon low potential conditions.

We also considered of interest to assess the stability of ATO tubes at potentials higher than those experienced in PEMFC. For instance, in PEMWE devices, where the reverse reactions occur, the voltages applied to split water into oxygen and hydrogen can surpass $1.5 \mathrm{~V}$. Unsupported electrocatalysts e.g. iridium metal or oxide ${ }^{24,25}$ are conventionally used at the anode, where the oxygen evolution reaction (OER) takes place, but in the last years there has been a growing use of support materials, in particular ATO, 26,27 that can promote better dispersion of the catalytic sites. It is essential to know the high potential limit of electrochemical stability of such supports in view of their possible integration in a proton exchange membrane water electrolyser.

Ex situ chronoamperometry was thus performed on bare supports at voltages as high as $2.0 \mathrm{~V} / \mathrm{RHE}$ and coupled with ICP-MS analysis of the liquid electrolyte to assess the stability of ATO tubes at high potential. Furthermore, PEMWE catalyst anode layers were prepared with $\mathrm{IrO}_{\mathrm{x}}$ supported on ATO and were integrated in an MEA. I/V curves were performed before and after polarisation at the limit potential of $2 \mathrm{~V}$ and any element leaching monitored by ICP-MS analysis. The electrodes was also characterised by XPS and ${ }^{119}$ Sn Mössbauer spectroscopies.

\section{Experimental}

2.1 Preparation of Pt/ATO and $\mathrm{IrO}_{\mathrm{x}} / \mathrm{ATO}$ 
$10 \%$ at. $\mathrm{Sb}$ doped $\mathrm{SnO}_{2}$ tubes (ATO) were prepared by electrospinning as reported elsewhere, ${ }^{11,22}$ and catalysed with highly monodisperse $\mathrm{Pt}^{10,28}$ and $\mathrm{IrO}_{\mathrm{x}}{ }^{29}$ nanoparticles synthesised by a microwave-assisted polyol method. The doping level (10 \%at. antimony) was guided by the electronic conductivity of the resulting doped oxide.

\subsection{Characterisation of ATO, Pt/ATO and IrO $\mathrm{x} /$ ATO}

The morphology of the electrospun ATO and Pt particles was characterised by field emission-scanning electron microscopy (FESEM) using a Hitachi S-4800 microscope and by transmission electron microscopy (TEM) using a JEOL 1200 EXII microscope operating at $120 \mathrm{kV}$, equipped with a CCD camera SIS Olympus Quemesa (11 million pixels). For TEM analysis, samples were suspended in ethanol and sonicated before deposition onto carbon-coated copper grids. The average diameter of the $\mathrm{Pt}$ and $\mathrm{IrO}_{\mathrm{x}}$ nanoparticles was determined by measuring 200 selected objects using the Image J software. ${ }^{30}$

Chronoamperometry measurements were carried out on ATO to investigate its stability at different potential values. Electrochemical analyses were carried out in a three-electrode cell comprising a titanium foil (geometric area $4 \mathrm{~cm}^{2}$ ) as working electrode, a reversible hydrogen electrode $(\mathrm{RHE})$ as reference electrode and a platinum wire as counter electrode, and using a BioLogic SP-150 potentiostat. Potentiostatic accelerated stress tests (AST) were performed by holding the working electrode potential at 1.5/1.6/.7/1.8/1.9/2.0 V/RHE for $4 \mathrm{~h}$ in $0.5 \mathrm{M} \mathrm{H}_{2} \mathrm{SO}_{4}$ at $80{ }^{\circ} \mathrm{C}$. The ink was prepared by dispersing $28 \mathrm{mg}$ of ATO in $6 \mathrm{~mL}$ ethanol/water solution ( $3 / 1 \mathrm{v} / \mathrm{v})$ and $136 \mu \mathrm{L}$ of $5 \%$ wt. Nafion ${ }^{\circ} \mathrm{EW} 1100$ dispersion (Aldrich). After ultrasonication, the entire volume was deposited onto the Ti foil by manual spraying on a hot plate at $70{ }^{\circ} \mathrm{C}$ to remove the solvent. Inductively coupled plasma-mass spectroscopy (ICP-MS, Agilent 7900) measurements of $10 \mathrm{~mL}$ of the electrolyte solution after chronoamperometry were performed after addition of $1 \mathrm{~mL}$ of aqua regia to dissolve any solids.

The amount of $\mathrm{Pt}$ and $\mathrm{IrO}_{\mathrm{x}}$ effectively supported on ATO was determined by X-ray fluorescence (XRF) with a PANalytical Axios Max spectrometer fitted with a Rh (4 kW) tube, and equipped with a LiF200 crystal and Omnian software. Samples were prepared by grinding $50 \mathrm{mg}$ of each electrocatalyst with $25 \mathrm{mg}$ of cellulose. The resulting powder was then placed in the centre of a cavity containing $\mathrm{H}_{3} \mathrm{BO}_{3}$ (acting as a matrix) and subsequently pressed, in order to obtain a pellet of $32 \mathrm{~mm}$ diameter with scanned surface of $c a .1 .1 \mathrm{~cm}^{2}$. The same protocol was used to prepare seven standards using 15, 20, 25, 30, 35, 40 and $45 \%$ wt of Pt black (Alfa Aesar), $\mathrm{IrO}_{2}$ (99.9\% Sigma Aldrich) and ATO to obtain a calibration line.

\subsection{Preparation of membrane electrode assemblies with Pt/ATO cathodes}

Gas diffusion electrodes (Sigracet 10BC, with a nominal loading of $0.5 \mathrm{mg} \mathrm{Pt} \mathrm{cm}^{-2}$ ) for the anode were purchased from Baltic Fuel Cell. Nafion 212 membranes (Ion Power) were treated as detailed elsewhere ${ }^{21}$ before assembly with the electrodes. A catalyst ink was prepared with $7.3 \mathrm{mg}$ of Pt/ATO (or $4.9 \mathrm{mg}$ HiSPEC 9100, Johnson Matthey Pt/C catalyst), $35.4 \mu \mathrm{L}$ (or $23.9 \mu \mathrm{L}$ ) of a $5 \%$ wt. Nafion ${ }^{\circ}$ EW1100 dispersion (Aldrich), $1.5 \mathrm{~mL}$ of water and $4.5 \mathrm{~mL}$ of ethanol. The ink was sonicated for 10 min and sprayed with an aerograph onto a $8 \mathrm{~cm}^{2}$ Teflon sheet placed over a heating pad at $80{ }^{\circ} \mathrm{C}$ until the target loading of $0.35 \mathrm{mg} \mathrm{Pt} \mathrm{cm}-2$ was reached. The resulting catalyst layer was transferred onto the Nafion ${ }^{\circledR} 212$ membrane to produce a Catalyst Coated Membrane (CCM). This was achieved by placing the membrane on the catalyst layer, and covering the membrane with a Teflon-glass fibre fabric. By hotpressing at $1400^{\circ} \mathrm{C}$ for $90 \mathrm{~s}$ at $18.8 \mathrm{MPa}$, the catalyst layer was transferred to the membrane. Finally, the anode and the GDL (Sigracet $10 \mathrm{BC}$ ) were hot-pressed in the same conditions to furnish the Membrane Electrode Assembly (MEA).

\subsection{PEMFC electrochemical characterisation}

The prepared MEAs were incorporated in single fuel cell hardware, and were conditioned at $0.4 \mathrm{~A} \mathrm{~cm}^{-2}$ overnight at $100 \% \mathrm{RH}$ and $80{ }^{\circ} \mathrm{C}$. Polarisation curves were recorded under $\mathrm{H}_{2} / \mathrm{O}_{2}$ (stoichiometry 1.5/2) in galvanostatic mode. A back-pressure of 1 bar was applied ( 2 bar absolute pressure). The MEAs were then submitted to on/off cycling, whereby a load of $1.5 \mathrm{~A} \mathrm{~cm}{ }^{-2}$ was applied to the cell ("on" phase) followed by a period of shutdown ("off" phase), where the load (current) was set to zero. The cell voltage was recorded during the "on" phase. The protocol was applied after measuring the beginning of test (BoT) stable average current density at $0.65 \mathrm{~V}$. This current density was taken as $100 \%$ current density of the on/off profile. The current density was then increased to $1.5 \mathrm{~A} \mathrm{~cm}^{-2}$ and maintained for $30 \mathrm{~min}$, and subsequently decreased to the previously recorded initial current density, where the cell voltage was measured. The load was then disconnected, the reactant supply at the cell inlet (without purging) stopped and the cell cooled down to room temperature. These conditions were held for 30 min, then the initial operating conditions were set again and the cycle repeated until the cell voltage at the recorded current density had decreased by $10 \%$ of its initial value, considered here as representing the end of test (EOT). For Pt/C and Pt/ATO, EoT corresponded to 35 cycles. Polarisation curves were measured at BoT and EoT.

To identify and quantify any degradation of the catalyst or support, $20 \mathrm{~mL}$ samples were withdrawn from the cathode exhaust water after every five start/stop cycles. $1 \mathrm{~mL}$ of aqua regia was added to dissolve any solids, and the solutions obtained were analysed by inductively coupled plasma-mass spectroscopy (ICP-MS, Agilent 7900). 2 L of exhaust water was recovered in total at the fuel cell cathode after EoT.

\subsection{Spectroscopic characterisation of Pt/ATO-based cathodes}

The surface chemical state of the Pt/ATO-based cathode catalyst layer before and after fuel cell testing was monitored by X-ray Photoelectron Spectroscopy (XPS) on an ESCALAB 250 spectrometer (Thermo Electron). The X-ray excitation was provided by a 
monochromatic Al $K_{\alpha}(1486.6 \mathrm{eV})$ source and the analysed surface area was $400 \mathrm{\mu m}^{2}$. A constant analyser energy mode was used for the electron detection ( $20 \mathrm{eV}$ pass energy). Detection of the emitted photoelectrons was performed perpendicularly to the sample surface. Data quantification was performed with the Avantage software, after removing the background signal using the Shirley method. The surface atomic concentrations were determined from photoelectron peak areas using the atomic sensitivity factors reported by Scofield. Binding energies of all core levels are referred to the C-C bond of C $1 \mathrm{~s}$ at $284.8 \mathrm{eV}$.

${ }^{119} \mathrm{Sn}$ Mössbauer spectroscopy was used to characterise the nature of the tin environment before and after the in situ AST. Spectra were recorded at room temperature with a constant acceleration spectrometer using a $\mathrm{Ca}^{119} \mathrm{SnO}_{3}$ source in transmission geometry, and they were fitted to combinations of Lorentzian lines. The absorbers used for the determination of the hyperfine parameters contained $1 \mathrm{mg} \mathrm{cm}^{-2}$ of the Pt/ATO, Pt/NTO powders. The counting time for the measurements was 74 hours in order to record high signal/noise spectra for each sample.

The chemical composition of the tin oxide based cathode layer was further investigated by scanning electron microscopy-energy dispersive X-ray spectroscopy (SEM-EDX) using a FEI Quanta FEG 200.

\subsection{Preparation of membrane electrode assemblies with $\mathrm{IrO}_{\mathrm{x}} / \mathrm{ATO}$ anodes}

MEA preparation was carried out as follows; for the anode side preparation, an ink was prepared by using 22.7 mg of IrO $/$ ATO dispersed in $\mathrm{H}_{2} \mathrm{O}$ :isopropanol (1:3) and $129.9 \mu \mathrm{L}$ of $5 \mathrm{wt}$. \% Nafion ${ }^{\circ}$ solution. After homogenisation in ultrasonic bath, the entire volume was deposited with a Nadetech Innovations ND-SP Spray Coater onto a $6.75 \mathrm{~cm}^{2}$ Teflon sheet placed over a heating pad at $80^{\circ} \mathrm{C}$ until a loading of $1 \mathrm{mg} \mathrm{cm}^{-2}$ was reached. The obtained electrode was transferred onto a Nafion 115 membrane (lon Power) previously treated using the procedure previously described. ${ }^{21}$ To prepare the $\mathrm{CCM}^{31}$ the membrane was placed over the electrode in a pre-heated press at $80^{\circ} \mathrm{C}$, and covered with Teflon-glass fibre fabric. The pressure was then increased to $8.1 \mathrm{MPa}$ and the temperature to $140{ }^{\circ} \mathrm{C}$. On reaching this temperature, the pressure was further increased to $15.7 \mathrm{MPa}$ for $45 \mathrm{~min}$. In a second step, the cathode ( $0.5 \mathrm{mg} \mathrm{Pt} \mathrm{cm}^{-2}$ supported on a Sigracet 10BC GDL from Baltic Fuel Cells) was hot pressed in the same conditions.

\subsection{PEMWE electrochemical characterisation}

The MEA prepared as in 2.6 was incorporated into the cell set-up using fluorinated ethylene propylene gaskets at 15-20 \% compression. Deionized water (Milli-Q quality, $18 \mathrm{M} \Omega$ ) was pumped through the anode with a flow rate of $200 \mathrm{~mL} \mathrm{~h}^{-1}$. The anode was previously flooded with deionized water. To characterize the cell, a Bio-Logic SP-150 Potentiostat with a 20 A booster was used. The MEA was conditioned at $80^{\circ} \mathrm{C}$ for 24 hours at $0.2 \mathrm{~A} \mathrm{~cm}^{-2}$ to ensure the full hydration of the membrane. Polarisation curves were recorded at $80^{\circ} \mathrm{C}$ by increasing the current density from 0 to $2 \mathrm{~A} \mathrm{~cm}^{-2}$ keeping the current density constant until the variation of the steady-state potential was less than $1 \mathrm{mV} \mathrm{min}{ }^{-1}$. To evaluate the stability of $\mathrm{IrO}_{x} /$ ATO, a polarisation curve was recorded after polarisation of the MEA at $2 \mathrm{~V}$ for 4 hours. After these measurements, ICP-MS was used to investigate any electrocatalyst degradation: $5 \mathrm{~L}$ of water were recovered from the anode side, and $20 \mathrm{~mL}$ were withdrawn and added with $1 \mathrm{~mL}$ of aqua regia to dissolve any solids. XPS and ${ }^{119} \mathrm{Sn}$ Mössbauer spectroscopy were used to characterise the anode after the polarisation at high potential.

\section{Results and Discussion}

\subsection{Morphological characterisation of Pt/ATO}

SEM micrographs of $10 \%$ at. Sb doped tin oxide electrospun tubes synthesised by single-needle electrospinning followed by calcination ${ }^{11,22}$ are shown in Figure S1a, Supporting Information. The Pt nanoparticles prepared by an optimised microwaveassisted polyol method ${ }^{10}$ and dispersed onto ATO displayed an average diameter of $3.5 \mathrm{~nm}$ (Figure S1b). The Pt loading evaluated by XRF was $37 \%$ wt. on ATO.

\subsection{In situ accelerated ageing of MEAs with Pt/ATO and Pt/C cathodes}

Pt nanoparticles supported on $\mathrm{Sb}$ doped $\mathrm{SnO}_{2}$ demonstrated exceptional ORR electroactivity in ex situ electrochemical characterisation, with mass activity of $0.27 \mathrm{~A} \mathrm{mg}^{-1} \mathrm{Pt}$ at $0.9 \mathrm{~V} / \mathrm{RHE}$, as well as excellent stability at high potential (1.6 V/RHE) with ca $80 \%$ ECSA and ca $65 \%$ mass activity retention after 6,000 cycles. These results are rationalised on the basis of the strong metalsupport interaction that promotes electroactivity and strengthens nanocatalyst anchoring ${ }^{10}$. Better stability of Pt/ATO than Pt/C when cycled in situ at high potential was also demonstrated. ${ }^{22}$ In the present work, MEAs were prepared by CCM instead of spraying the catalytic ink on the GDL (to form a gas diffusion electrode, GDE) and using Pt nanocatalysts prepared with the modified synthesis, leading to an exceptional performance comparable to that of Pt on carbon. In Figure 1 is depicted the initial performance of the MEA comprising a Pt/ATO cathode catalyst layer compared to that of an MEA comprising a Pt/C catalyst prepared in an otherwise identical fashion. This figure also provides the I-V curves given by the two MEAs after completion of the accelerated ageing protocol described in section 2.4 . 


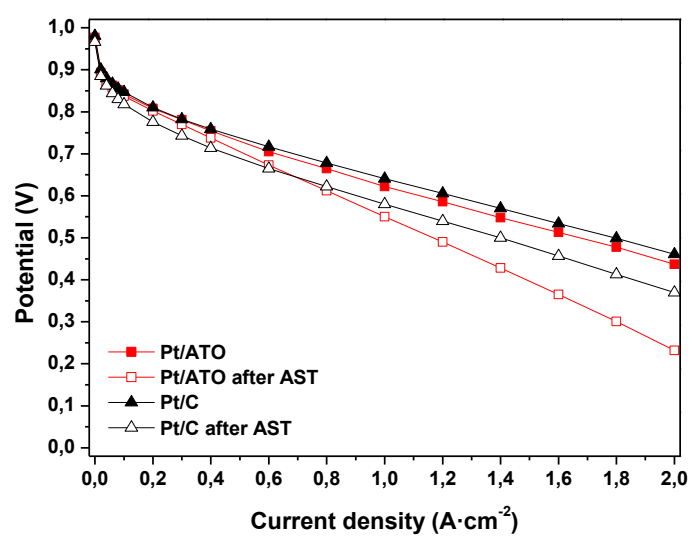

Figure 1. Polarisation curves of MEAs including cathodes with Pt deposited on ATO and carbon (with loading of $0.35 \mathrm{mg} \mathrm{Pt} \mathrm{cm}^{-2}$ ) at $80{ }^{\circ} \mathrm{C}$ and $100 \%$ RH before and after 35 load cycles (56 hours).

The polarisation curve of the MEA comprising the Pt/ATO cathode catalyst layer is practically identical to that given by the MEA with a Pt/C cathode, throughout the current density range to $2 \mathrm{~A} \mathrm{~cm}^{-2}$. Both catalysts had similar Pt loading $\left(0.35 \mathrm{mg} \mathrm{Pt} \mathrm{cm}^{-2}\right)$. This is a remarkable result, which is consistent with the high mass activity of the Pt/ATO catalyst determined with a rotating disk electrode, ${ }^{10}$ as well as the high electrical conductivity of the metal oxide support (almost reaching that of carbon) ${ }^{22}$ that leads to low resistance of the catalyst layer. The support surface area is sufficient to allow for a Pt loading of $37 \%_{\mathrm{wt}}$, which enables the preparation of a thin, low resistance catalyst layer that did not give greater mass transport resistance than the Pt/C layer. The strong anchoring and thus electrical connectivity between Pt particles and support, ${ }^{10}$ and the deposition method used to prepare the electrocatalyst layer may also play crucial roles. Indeed, in our previous work, electrodes prepared by spraying similarly prepared electrocatalysts onto GDLs led to lower power densities than those reported here at $0.6 \mathrm{~V}\left(0.61 \mathrm{~W} \cdot \mathrm{cm}^{-2}, 1.6 \mathrm{~A} \cdot \mathrm{cm}^{-2}\right)$ despite a higher Pt loading of $0.5 \mathrm{mg} \mathrm{Pt} \mathrm{cm}^{-2} .{ }^{21,22}$ It is concluded that the optimised Pt particle size, deposition and post-treatment ${ }^{10}$ as well as the CCM method used in this work provide more effective fuel cell catalyst layers. Dou et al. reported similar performance as that described here, for Pt/ATO and commercial Pt/C-based MEAs prepared by spraying the catalyst ink on the GDL. ${ }^{32}$ On the other hand, Mohanta et al., who also used the CCM method as in this work, reported significantly lower performance of an MEA with Pt/ATO cathode than with Pt/C in single cell tests with $\mathrm{H}_{2}$ /air. ${ }^{8}$ Kakinuma et al. also reported lower performance for a Pt/ATO-cathode MEA compared to Pt/C or Pt/NTO-based MEAs, all of them based on GDEs, and attributed this finding to Pt poisoning by $\mathrm{Sn}$ dissolution and reprecipitation ${ }^{14}$. This phenomenon, occurring only for the Sb doped oxide, was avoided by operating at potentials $>0.4 \mathrm{~V}$, where the Pt/ATO-based MEA was observed to out-perform that with the Pt/C cathode.

Several groups have reported studies of $\mathrm{Pt} / \mathrm{SnO}_{2}$-based MEAs using high potential accelerated stress tests. ${ }^{12,14,21,22}$ Due to the high corrosion resistance of the tin oxide support, in these conditions these cathodes have reproducibly displayed higher durability than carbon-based ones. For instance, in previous work we observed that Pt/ATO tubes suffered no significant degradation after 1,200 cycles under 0.9-1.4 $\mathrm{V}$ potential excursions. ${ }^{21,22}$ The $\mathrm{i} / \mathrm{V}$ curves before and after the high voltage cycling were practically superimposable. ${ }^{22}$

In contrast, the polarisation curves obtained before and after load cycles with Pt/ATO and Pt/C based MEAs are shown in Figure 1. This accelerated stress test mimics start/stop conditions and differs from previous work by reaching high current density, i.e. quite low potentials, instead of high potentials/low current density.

The initial open circuit voltages (OCV), around $0.97 \mathrm{~V}$ for Pt/ATO based MEAs and $0.99 \mathrm{~V}$ for Pt/C based MEA, were practically unchanged after 35 start/stop cycles. At higher current density values, the performance of the Pt/C-based MEAs slightly decreased, while that of the Pt/ATO cathode diminished strongly, from 0.53 to $0.40 \mathrm{~V}$ at $1.5 \mathrm{~A} \mathrm{~cm}^{-2}$. This significant performance drop for the assembly comprising $\mathrm{Sb}$ doped $\mathrm{SnO}_{2}$ can be related to the specific instability of this support in low potential conditions. As explained above, Pt/ATO electrocatalysts were previously reported to present degradation in fuel cell operation in similar low potential conditions $\left(\mathrm{E}<0.4 \mathrm{~V}\right.$ ), which was attributed to $\mathrm{Sn}$ dissolution/redeposition from the $\mathrm{SnO}_{2} \cdot{ }^{14,33} \mathrm{Another}$ possible explanation for the instability of the Pt/ATO is the segregation and consequent dissolution of antimony species, leading to lower electrical conductivity that impacts fuel cell performance ${ }^{34}$. Indeed, the segregation of $\mathrm{Sb}$ at the surface of electrospun ATO loosetubes has been already shown by XPS. ${ }^{10}$ The instability of antimony species in ATO at low potentials (<0.36 V/RHE) was earlier demonstrated in electrochemical tests by means of a scanning flow cell. ${ }^{35}$ Using ex situ electrochemical characterisation of Pt/ATO aerogels, Cognard et al. concluded that at low potential (0.1 V/RHE), Sb atoms back-spillover from ATO, adsorb onto the Pt nanoparticle surface and block the catalytic sites. ${ }^{33}$ At higher potential values $(0.7 \mathrm{~V} / \mathrm{RHE})$, they are stripped and dissolved into the electrolyte. The adsorption of $\mathrm{Sb}$ adatoms on $\mathrm{Pt}$ surfaces was already reported to leading to suppression of hydrogen adsorption/desorption, thus blocking of active sites. ${ }^{36}$

Thermodynamic calculations show that at low pH ( $c a 0)$ et low potential ( $c a$ 0.4/RHE) antimony is present as soluble species (soluble oxides $\mathrm{Sb}_{2} \mathrm{O}_{3}$ and $\mathrm{Sb}_{2} \mathrm{O}_{5}$, and $\left.\mathrm{SbO}^{+}\right)^{37}$, giving further insights on the preferential leaching of $\mathrm{Sb}$ in the on/off test conditions. From the present results, the onset of the degradation of ATO tubes is observed already at $0.5 \mathrm{~V}$. 
In order to evaluate the stability of tin and antimony in Pt/ATO upon load cycling and identify the origin of the decrease of the Pt/ATO cathode performance, several probe spectroscopic methods were deployed here to investigate the eventual modification of the end of test chemical composition $(\mathrm{Sn}, \mathrm{Sb})$ of the supports and describe the degradation mechanism taking place.

\subsection{Characterisation of MEA with Pt/ATO cathode at end of test}

To evaluate the eventual loss of elements during the on/off cycling, the chemical composition of exhaust water recovered at the fuel cell Pt/ATO cathode was analysed. In particular, traces of the elements composing the cathode materials ( $\mathrm{Pt}, \mathrm{Sn}, \mathrm{Sb}$ ) were analysed by ICP-MS every 5 AST cycles, and the results are depicted in Figure 2. No significant amount of Sn (or Pt) was detected, differently from what is reported for ex situ ${ }^{33}$ and in situ ${ }^{14}$ tests in similar load cycling operation conditions (Figure $2 \mathrm{~b}, \mathrm{~d}, \mathrm{f}$ ). In contrast, a high concentration of Sb (7.1 $\mu \mathrm{g} / \mathrm{L}$ ) was detected in the exhaust water. In particular, a peak indicating a sharp increase of $\mathrm{Sb}$ leaching is observed at the $20^{\text {th }}$ cycle, which may be ascribed to the progressive segregation of $\mathrm{Sb}$ to the support surface during cycling, followed by its loss to the electrolyte.

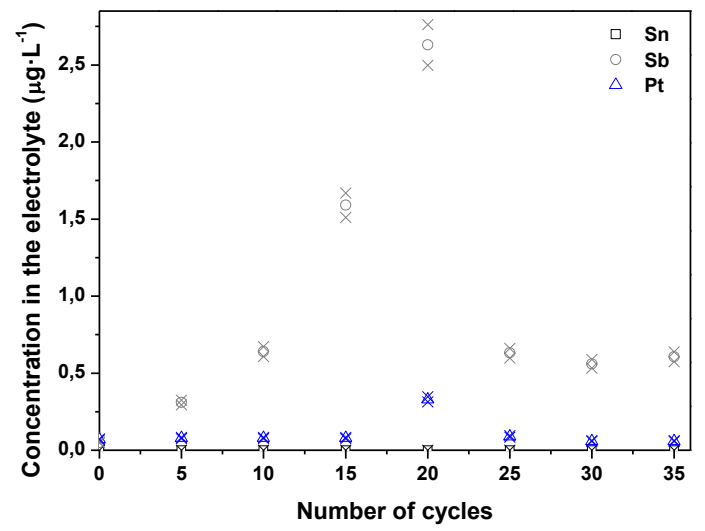

Figure 2. ICP-MS analysis of $\mathrm{Sn}, \mathrm{Pt}$ and $\mathrm{Sb}$ detected in the cathode exhaust water during load cycling AST on Pt/ATO-based MEAs.

Other experimental techniques were employed to probe the supported catalyst material. X-ray photoelectron spectroscopy (XPS) was carried out to investigate the effect of the AST on the chemical state of the surface of the Pt/ATO-based cathodes. In particular the analysis was performed on the catalyst layers at the cathode side on all the elements present (Pt, Sn, $\mathrm{Sb}$, and O) before and after on/off cycling.

In Figure 3 are depicted the XPS core level spectra of Sn3d for Pt/ATO (spectrum 1). A doublet at $487.6 \mathrm{eV}$ and $496.0 \mathrm{eV}$ is present, which can be assigned to Sn(IV). ${ }^{38,39}$ However, the difficulty in distinguishing Sn(IV) from Sn(II) by XPS is well-known and should be kept in mind. ${ }^{11}$ No changes were detected in the Sn3d binding energies after start/stop cycling (spectrum 2), indicating that this element was not significantly affected by the accelerated stress test.

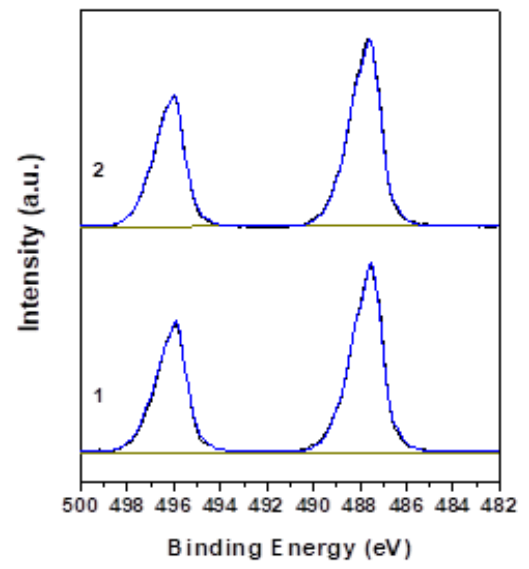

Figure 3. XPS core level spectra of Sn3d before (1) and after (2) start/stop cycling AST for Pt/ATO cathode.

The study of the XPS spectra of the Sb dopant will give further information for discussion and interpretation. The Sb3d region (Figure 4) for BoT (1) and EoT (2) of the Pt/ATO cathode was investigated. The Sb3d and O1s regions are overlapped, and thus peak deconvolution was performed to separate the respective contributions. Five components are evident: at $531.5 \mathrm{eV}$ (band $\mathrm{A}$ ) the peak is related to $\mathrm{O}^{2-}$ ions in an oxide lattice structure, at $531.9 \mathrm{eV}$ (band $\mathrm{B}$ ) to $\mathrm{Sb}_{3} \mathrm{~d}_{5 / 2}\left(\mathrm{Sb}(\mathrm{V})\right.$ ), ${ }^{40-42}$ at $532.4 \mathrm{eV}\left(\right.$ band C) to $\mathrm{H}_{2} \mathrm{O}, \mathrm{OH}$ or CO species adsorbed on the surface, ${ }^{43,44}$ at $535.2 \mathrm{eV}$ (band D) to ether groups in the Nafion ${ }^{\bullet}$ ionomer present in the catalyst layer, ${ }^{45}$ at $541.1 \mathrm{eV}$ (band $\left.\mathrm{E}\right)$ to ${\mathrm{Sb} 3 \mathrm{~d}_{3 / 2}(\mathrm{Sb}(\mathrm{V})) .41,42,46,47}$ 


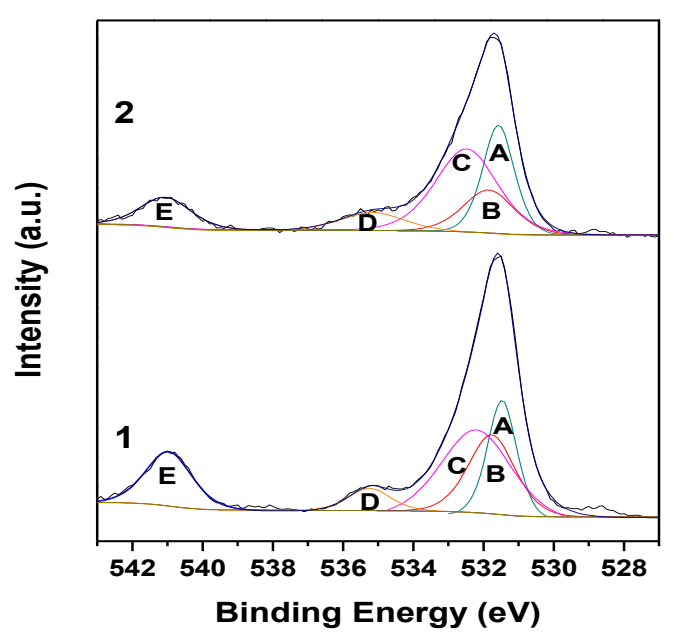

Figure 4. XPS core level spectra of Sb3d and O1s for Pt/ATO cathode before (1) and after (2) start/stop cycling AST. A) O2- ions in the oxide; B-E) Sb(V) doublet; C) adsorbed oxygenated species; D) ether groups in Nafion.

The Sb3d spectrum for the Pt/ATO cathode after the load cycling (2) is very similar to that of the BoT sample (1), and XPS analysis provided no evidence of a change in the degree of oxidation for the elements comprising the electrocatalyst/support surface. However, the loss of antimony seen in the ICP-MS study was confirmed by the decrease of the Sb/Sn ratio from 0.17 to 0.11 after load cycling. $41,46,48$

The Pt4f region was also evaluated for the Pt/ATO cathode before (1) and after (2) the load cycling (Figure 5). For the pristine cathode, a doublet corresponding to $\mathrm{Pt}_{4} \mathrm{f}_{7 / 2}$ and $\mathrm{Pt} 4 \mathrm{f}_{5 / 2}$ at 71.4 and $74.7 \mathrm{eV}$ (A bands), indicating metallic Pt, and a doublet at higher energy ( $\mathrm{B}$ bands) corresponding to $\mathrm{PtO}_{\text {ads }}$ were observed. ${ }^{49} \mathrm{After}$ the load cycling, the $\mathrm{Pt} / \mathrm{Pt}^{2+}$ ratio was practically unchanged (1.36). The $\mathrm{Pt} / \mathrm{Sn}$ ratio showed a decrease of $c a .22 \%$ from 0.36 to 0.28 , which seems to indicate a partial loss of platinum after on/off cycling.

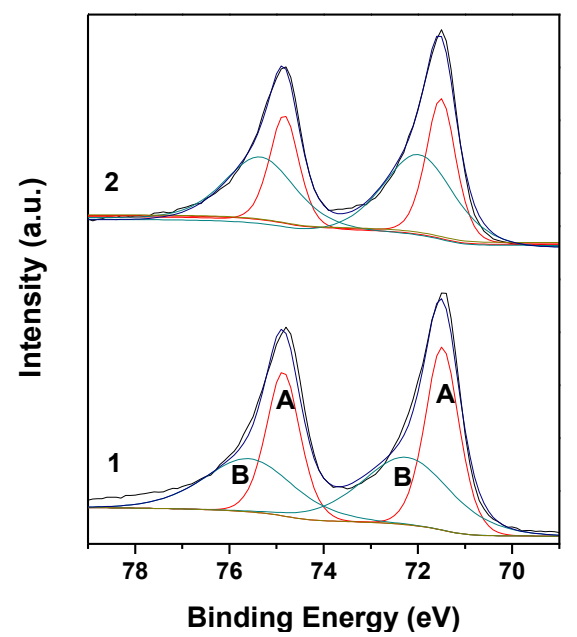

Figure 5. XPS core level spectra of Pt4f before (1) and after (2) start/stop cycling AST for Pt/ATO (b) cathode. A) Pt(0) dou blet; B) PtO adsorbed species.

In order to better evaluate the oxidation state of tin in the Pt/ATO cathode, still controversial in XPS, and its eventual modification (reduction) after the AST, the materials were also characterised by ${ }^{119} \mathrm{Sn}$ Mössbauer spectroscopy. The results are compared to those obtained on a non-doped pristine sample synthesised in the same way. ${ }^{11}$ Figure 6 displays the spectra as well as the corresponding parameters (isomer shift, $\delta$, and quadrupole coupling constant, $e^{2} q Q$ ). The results obtained indicated in all cases the presence of only $\mathrm{Sn}^{4+}$, and neither $\mathrm{Sn}^{2+}$ nor metallic $\mathrm{Sn}$ were detected. The non-zero quadrupole splitting is indicative of the presence of oxygen vacancies around $\mathrm{Sn}^{4+}$ ions, while the isomer shift is slightly different from that of non-doped $\mathrm{SnO}_{2}$ tubes $(\delta=$ $0 \mathrm{mms}^{-1}$ ), which suggests a small variation in the $\mathrm{Sn}-\mathrm{O}$ bond length in ATO compared to that in $\mathrm{SnO}_{2}$. Line widths, $\Gamma=0.88 \mathrm{~mm} \mathrm{~s}{ }^{-1}$, are similar for doped and undoped $\mathrm{SnO}_{2}$ and indicative of small particle size. The Mössbauer spectra of the Pt/ATO cathode layer before and after the load cycling are practically identical. The only minor difference is a slight decrease of the isomer shift from

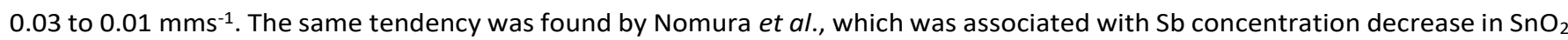
films. ${ }^{50}$ However, here the variation is negligible, so no certain assumption about the Sb loss can be inferred. These results corroborate the conclusion that the degradation of the activity of the Pt/ATO cathode is due to Sb (rather than Sn) instability in the support during excursions to low potential. 
The leaching of elements identified by the above characterisation may lead to material degradation or particle agglomeration and detachment, which could explain the evolution of $\mathrm{i} / \mathrm{V}$ curves during the load cycling. To investigate this possibility, the morphology and chemical composition of the Pt/ATO-based cathodes were followed by FE-SEM and EDX (Figure 7). Clearly, the overall fibrein-tube morphology is retained after on/off cycling.

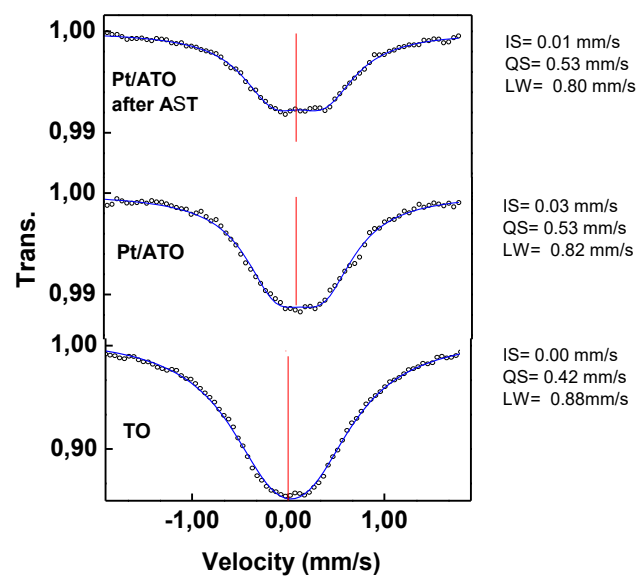

Figure 6. ${ }^{119} \mathrm{Sn}$ spectra of Pt/ATO catalyst layers before and after load cycling accelerated stress test and comparison with undoped tin oxide (TO) fibres.

A slight decrease of the Pt/Sn atomic ratio from 0.38 to 0.34 after the AST was observed, in agreement with the low level of Pt leaching detected by ICP-MS analysis. Furthermore, the EDX-determined Sb/Sn atomic ratio dropped from 0.18 at BoT to 0.13 at EoT, in agreement with the detection of $\mathrm{Sb}$ ions in the cathode exhaust water by ICP-MS.
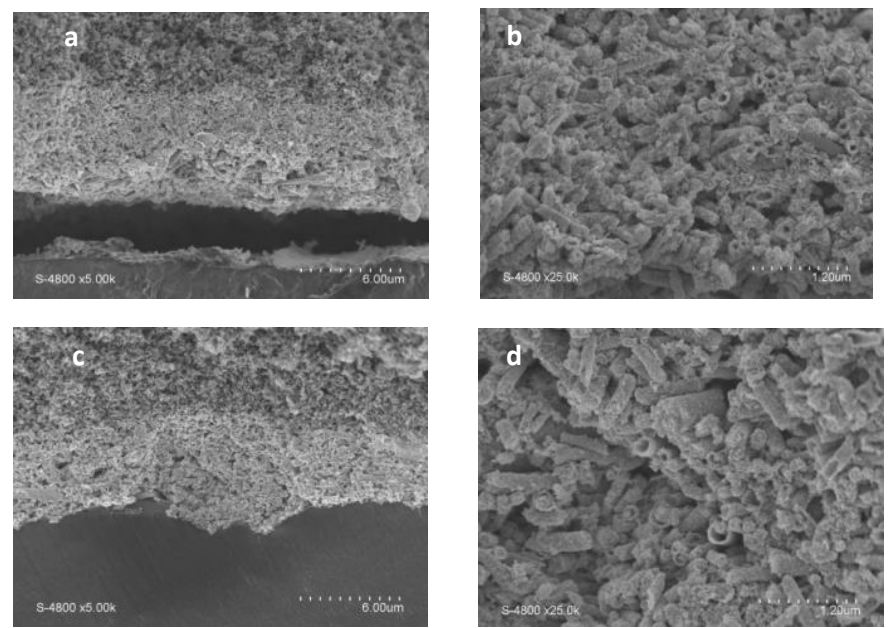

Figure 7. SEM micrographs of Pt/ATO-based cathodes before $(a, b)$ and after the AST (c, d).

All the spectroscopic and analytical probes employed to investigate the Pt/ATO-cathode and the corresponding exhaust water converge in confirming the drop in performance in fuel cell test with the low (electro)chemical stability in on/off cycling conditions. No modification of the oxidation state of the atoms comprising the support or the catalyst materials was observed. From this work, it is concluded that the performance loss of the MEA with Pt/ATO cathode upon experiencing low potentials cannot be attributed to the dissolution of tin as reported elsewhere ${ }^{14,33}$, but rather to the dissolution of the antimony doping agent that is detrimental to the cathode properties at various levels. The surface segregation of Sb, followed by its sublimation or dissolution, already reported to occur upon high temperature or prolonged annealing and voltage cycling, is a reasonable explanation of this phenomenon. ${ }^{34}$ On the one hand, Sb leaching will lead to a decrease in the electrical conductivity of the support $22,34,35$, which can lead to both ohmic drop and local deactivation of the Pt catalyst. On the other hand, leached antimony atoms can adsorb onto the Pt surface and block the active sites ${ }^{33}$, prior to being stripped and lost into solution.

\subsection{EX situ characterisation of ATO at potentials $\geq 1.5 \mathrm{~V} / \mathrm{RHE}$}

In the context of PEMWE application, the stability of ATO tubes was evaluated at potentials higher than those experienced in PEMFC using ex situ and in situ electrochemical characterisation, by submitting ATO to increasing potentials from 1.5/RHE to 
2.0/RHE in acidic medium. Every step consisted of a $0.1 \mathrm{~V}$ increase in potential and had a duration of 4 hours. Oxidation currents were followed by chronoamperometry, while the support integrity was monitored by analysing any Sn and Sb ions eventually released into the electrolyte by ICP-MS (Figure 8). Negligible corrosion current and charge were observed, in agreement with the expected metal oxide corrosion resistance ${ }^{51,52}$. Elemental analysis of the electrolyte showed that both tin as well as antimony dopant are leached under these conditions. The detected Sn amount was negligible $\left(5.5 \mu \mathrm{g} \mathrm{L}^{-1} \mathrm{up}\right.$ to $1.8 \mathrm{~V} / \mathrm{RHE}, 17 \mu \mathrm{g} \mathrm{L}-1$ at 1.9 $\mathrm{V} / \mathrm{RHE}$, and $64.2 \mu \mathrm{g} \mathrm{L}^{-1}$ at $\left.2.0 \mathrm{~V} / \mathrm{RHE}\right)$. The Sb amount released was greater, and, although negligible up to $1.9 \mathrm{~V} / \mathrm{RHE}^{2}(22.6 \mu \mathrm{g} \mathrm{L}-1$ to $59.8 \mu \mathrm{g} \mathrm{L}^{-1}$, Figure 8), when a potential of $2.0 \mathrm{~V} / \mathrm{RHE}$ was applied to ATO, a step change in antimony release was detected ( $371 \mu \mathrm{g}$ $\left.\mathrm{L}^{-1}\right)$. It may be concluded from these results that the loss of elements into solution is not due to $\mathrm{Sb}-\mathrm{SnO}_{2}$ detachment from the electrode, but to preferential leaching of antimony at high potential as already reported. ${ }^{34}$ As discussed above, the loss of the $\mathrm{Sb}$ dopant leads to a decrease of the electrical conductivity of the oxide support, with subsequent loss of performance of the electrode. Therefore, for the optimal performance of ATO as support for OER electrocatalysts in PEMWE, 1.9 V/RHE should be considered as the potential limit. Further data to support this conclusion are given by the in situ characterisation of the catalysed support material $\mathrm{IrO}_{x} /$ ATO described in the following paragraphs.

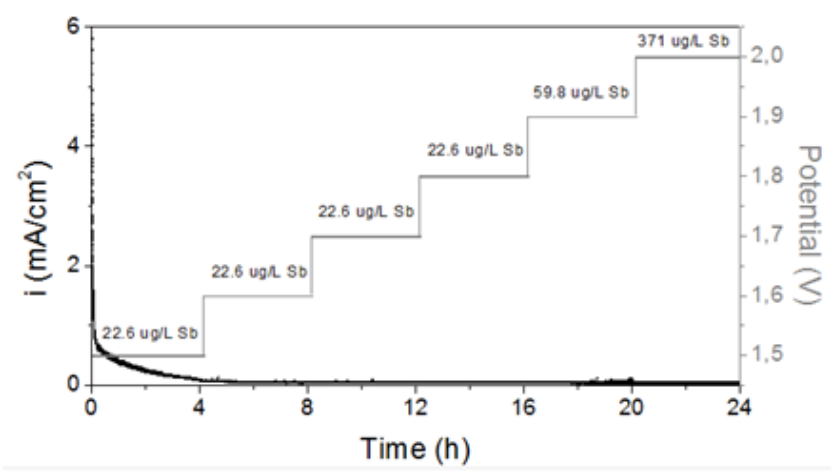

Figure 8. Coupling of chronoamperometry results on ATO supports at $1.5-2.0 \mathrm{~V}$ with ICP-MS analytical results of the liquid electrolyte (10 mL) after every $4 \mathrm{~h}$ step.

\subsection{In situ characterisation of the stability of IrO $_{x}$ /ATO-based MEAs}

$\mathrm{IrO}_{\mathrm{x}}$ nanoparticles were prepared by microwave-assisted polyol method ${ }^{29}$ and dispersed onto ATO. Their average diameter is 1.1 $\mathrm{nm}$ (Figure SI2), and the catalyst loading on ATO evaluated by XRF was $23 \%_{\text {wt. }}$. An MEA having an IrO $/ \mathrm{ATO}_{\mathrm{A}}$ anode side characterised in an electrolysis cell at $80{ }^{\circ} \mathrm{C}$, and the corresponding polarisation curve is depicted in Figure 9a. The MEA provided an average voltage of $1.71 \mathrm{~V}$ at $1 \mathrm{~A} \mathrm{~cm}^{-2}$ and $1.92 \mathrm{~V}$ at $2 \mathrm{~A} \mathrm{~cm}^{-2}$. The stability of IrO $_{x} / \mathrm{ATO}$ at high potential was evaluated by monitoring the evolution of the polarisation behaviour and of the chemical composition of the electrocatalyst after polarisation of the MEA at 2 $\checkmark$ for 4 hours, similar to the conditions used in the ex situ characterisation. As expected after this potentiostatic hold, the cell overpotential was higher, being $1.80 \mathrm{~V}$ at $1 \mathrm{~A} \mathrm{~cm}^{-2}$, and $2.10 \mathrm{~V}$ at $2 \mathrm{~A} \mathrm{~cm}^{-2}$; in particular the ohmic contribution increased at density currents $>200 \mathrm{~A} \mathrm{~cm}^{-2}$ (Figure 9b).

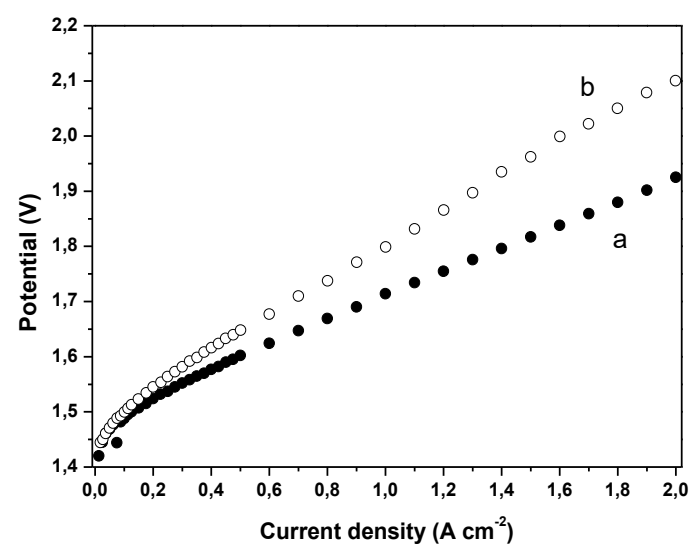

Figure 9. $\mathrm{I} / \mathrm{V}$ curves at $80^{\circ} \mathrm{C}$ for MEAs comprising $\mathrm{IrO}_{\mathrm{x}} / \mathrm{ATO}$ at the anode side before (a) and after (b) polarisation at $2 \mathrm{~V}$ for 4 hours.

ICP-MS analysis of anode exhaust water showed that tin and antimony were leached from the catalyst layer. The detected Sn amount was negligible $\left(0.08 \mu \mathrm{g} \mathrm{L}^{-1}\right)$, and significantly lower than the amount of the released Sb $\left(2.2 \mu \mathrm{g} \mathrm{L}^{-1}\right)$, demonstrating the preferential leaching of the doping agent. This result is further confirmed by EDX-SEM analysis (not shown), which demonstrated that the $\mathrm{Sb} / \mathrm{Sn}$ atomic ratio decreased to $8 \%$ after polarisation at $2 \mathrm{~V}$. A low amount of iridium from the deposited catalyst was also detected in the exhaust water $\left(0.11 \mu \mathrm{g} \mathrm{L}^{-1}\right)$. The observed increase in the MEA resistance can be thus rationalised by the decrease in the doping amount in the tin oxide support, with overall decrease in its electrical conductivity. The electrolysis cell 
testing results confirm that the upper potential limit of utilisation of ATO to preserve its chemical composition and properties is < $2 \mathrm{~V} / \mathrm{RHE}$.

It is relevant to note that the $2 \mathrm{~V} / \mathrm{RHE}$ limit corresponding to the step change in stability exceeds the 1.5/RHE limit already reported in several studies, ${ }^{33-35}$ although a low level degradation regime is observed at $1.5 \mathrm{~V} / \mathrm{RHE}$. The electrochemical stability of ATO strongly depends on the existing surface segregation of the doping agent, which in turn is related to the applied thermal treatment ${ }^{34}$ during the synthesis.

The electrode composition was examined following polarisation at $2 \mathrm{~V}$ with XPS and ${ }^{119} \mathrm{Sn}$ Mössbauer spectroscopies. The latter indicated that no change of the oxidation state occurred, as the obtained spectrum and calculated parameters correspond to those of undoped ATO (Figure 10). This result was expected because, as this technique already demonstrated, the support was in its highest oxidation degree $\left(\mathrm{Sn}^{4+}\right)$. No differences were detected for $\mathrm{IrO}_{\mathrm{x}} /$ ATO before and after the polarisation at high potential, except a slight reduction of $\delta$ from 0.14 to $0.10 \mathrm{~mm} \mathrm{~s}^{-1}$.

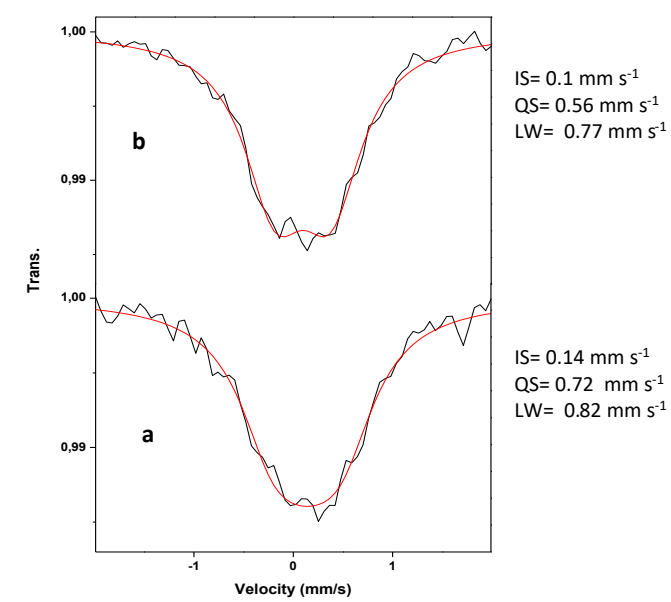

Figure 10. 119Sn Mössbauer spectra of $\mathrm{IrO}_{\mathrm{x}} /$ ATO catalyst layers before (a) and after (b) polarisation at $2 \mathrm{~V}$.

XPS analysis of the $\mathrm{IrO}_{x} /$ ATO electrode after high potential polarisation showed the same Sn3d, O1s and Sb3d signals at identical positions as the materials before the electrochemical characterisation (Figure 11), meaning no change in the oxidation state of the various elements.
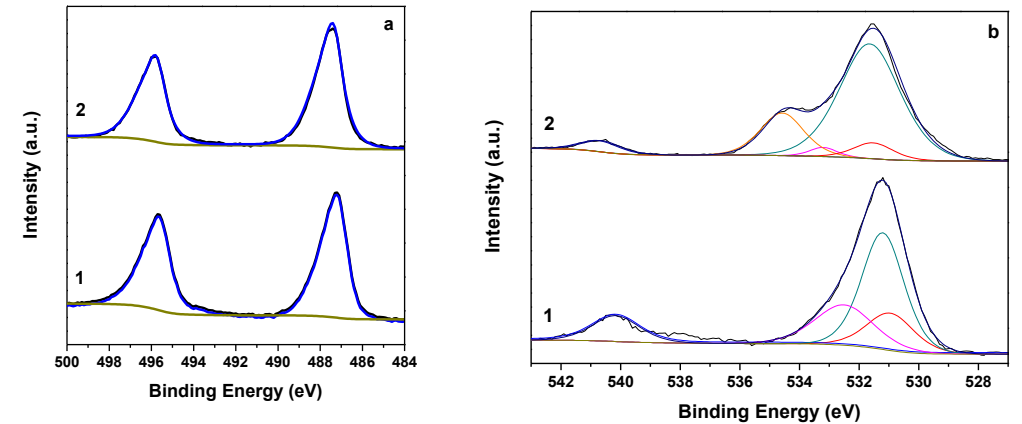

Fig 11. XPS core level spectra of Sn3d (a) and O1s/ Sb3d (b) for IrO $/$ /ATO anode before (1) and after (2) polarisation at $2 \mathrm{~V}$.

However, a significant reduction of the $\mathrm{Sb} / \mathrm{Sn}$ atomic ratio by 5.9 at\% was observed. It can be concluded that the loss of performance in electrolysis cell can be mainly ascribed to a reduced conductivity related to the loss of Sb from the surface of the support material.

\section{Conclusions}

This study on bare and catalysed ATO electrospun tubes with ex situ and in situ electrochemical and spectroscopic techniques allowed to determine the potential window for its optimal utilisation as electrocatalyst support in proton exchange membrane fuel cells and water electrolysers. The lower ( $0.5 \mathrm{~V} / \mathrm{RHE})$ and upper limits (2.0 V/RHE) are different from those reported in other studies on ATO materials, ${ }^{14,33-35}$ highlighting that the stability of the oxide strongly depends on the existing surface segregation of $\mathrm{Sb}$, which in turn depends on the synthesis conditions ${ }^{34}$.

Despite the high stability of Pt/ATO after cycling to relatively high voltages (1-1.6 ex situ ${ }^{10}$ and 0.9-1.4 $\mathrm{V}$ in situ ${ }^{22}$ ), the performance of MEAs with a PEMFC cathode comprising Pt/ATO significantly decreased after load cycling comprising excursions to low 
potentials. Microscopy and probe spectroscopic techniques applied to the materials at end of test, as well as on the exhaust water recovered at the cathode side, show that Sb leaching occurs at the low potential conditions, leading to increased support electrical resistance, catalyst local deactivation and/or blocking of catalyst active sites, which cause performance loss.

Excursion to potential higher than that typically used in proton exchange membrane fuel cell accelerated stress tests were investigated with the objective of assessing the upper potential limit for application of ATO at the anode of a PEM water

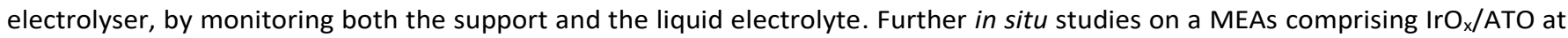
the anode confirmed that potentiostatic hold at $2 \mathrm{~V}$ led to Sb leaching with significant decrease in PEMWE performance. The established stability of electrospun ATO tubes at potentials up to $1.9 \mathrm{~V} / \mathrm{RHE}$ paves the way for the optimal exploitation of its high electronic conductivity and strong interaction with metal catalyst in high-potential applications such as water electrolysis anodes.

\section{Conflicts of interest}

There are no conflicts to declare

\section{Acknowledgements}

The research leading to these results has received funding from the European Research Council under the European Union's Seventh Framework Programme (FP/2007-2013) / ERC Grant Agreement n. 306682 and from the Project PEMFC-SUDOE SOE1/P1/E0293, which is co-financed by the European Regional Development Fund in the framework of the INTERREG SUDOE programme.

SC thanks the French IUF for its support. I. J.-M. acknowledges financial support from the French National Research Agency under the MOISE contract (ANR-12-PRGE-0007). The authors thank Dr. Moulay Sougrati for Mössbauer spectroscopic characterisation.

\section{Notes and references}

1. N. R. Elezovic, B. M. Babic, V. R. Radmilovic and N. V. Krstajic, J. Electrochem. Soc., 2013, 160, F1151.

2. A. Martyla, M. Kopczyk, P. Marciniak and R. Przekop, Chem. Cent. J., 2014, 8, 49.

3. A. Masao, S. Noda, F. Takasaki, K. Ito and K. Sasaki, Electrochem. Solid-State Lett., 2009, 12, B119.

4. G. Liu, J. Xu, Y. Wang and X. Wang, J. Mater. Chem. A, 2015, 3, 20791.

5. V. Avila-Vasquez, J. C. Cruz, M. Galván-Valencia, J. Ledesma-Garcia, L. G. Arriaga, C. Guzmán and S. M. Duron-Torres, Int. J. Electrochem. Sci., 2013, 8, 10586.

6. B. Rodríguez-García, Á. Reyes-Carmona, I. Jiménez-Morales, M. Blasco-Ahicart, S. Cavaliere, M. Dupont, D. Jones, J. Rozière, J. R. Galán-Mascarós and F. Jaouen, Sustain. Energy Fuels, 2018, 2, 589.

7. M. Dou, M. Hou, D. Liang, W. Lu, Z. Shao and B. Yi, Electrochim. Acta, 2013, 92, 468.

8. P. K. Mohanta, C. Glökler, A. O. Arenas and L. Jörissen, Int. J. Hydrogen Energy, 2017, $2,1$.

9. K. Kakinuma, M. Uchida, T. Kamino, H. Uchida and M. Watanabe, Electrochim. Acta, 2011, 56, 2881.

10. I. Jiménez-Morales, S. Cavaliere, D. Jones and J. Rozière, Phys. Chem. Chem. Phys., 2018, 20, 8765.

11. S. Cavaliere, S. Subianto, I. Savych, M. Tillard, D. J. Jones, J. Rozière and D. J. Jones, J. Phys. Chem. C, 2013, 117, 18298.

12. K. Kanda, Z. Noda, Y. Nagamatsu, T. Higashi, S. Taniguchi, S. M. Lyth, A. Hayashi and K. Sasaki, ECS Electrochem. Lett., 2014,3, F15.

13. Y. Senoo, K. Kakinuma, M. Uchida, H. Uchida, S. Deki and M. Watanabe, RSC Adv., 2014, 4, 32180.

14. K. Kakinuma, Y. Chino, Y. Senoo, M. Uchida, T. Kamino, H. Uchida, S. Deki and M. Watanabe, Electrochim. Acta, $2013,110,316$.

15. G. Ozouf and C. Beauger, J. Mater. Sci., 2016, 51, 5305.

16. J. Suffner, S. Kaserer, H. Hahn, C. Roth and F. Ettingshausen, Adv. Energy Mater., 2011, 1, 648.

17. F. Takasaki, S. Matsuie, Y. Takabatake, Z. Noda, a. Hayashi, Y. Shiratori, K. Ito and K. Sasaki, J. Electrochem. Soc., 2011,158, B1270.

18. Y. Senoo, K. Taniguchi, K. Kakinuma, M. Uchida, H. Uchida, S. Deki and M. Watanabe, Electrochem. Commun., $2015,51,37$.

19. S. Chen, Int. J. Electrochem. Sci., 2017, 12, 6221-6231.

20. G. Cognard, G. Ozouf, C. Beauger, I. Jiménez-Morales, S. Cavaliere, D. Jones, J. Rozière, M. Chatenet and F. Maillard, Electrocatalysis, 2017, 8, 51.

21. I. Savych, S. Subianto, Y. Nabil, S. Cavaliere, D. Jones and J. Rozière, Phys. Chem. Chem. Phys., 2015, 17, 16970-16976.

22. S. Cavaliere, I. Jiménez-Morales, G. Ercolano, I. Savych, D. Jones and J. Rozière, ChemElectroChem, 2015, 2, 1966.

23. G. Tsotridis, A. Pilenga, G. De Marco and T. Malkow, EU Harmonised Test Protocols for PEMFC MEA Testing in Single Cell Configuration for Automotive Applications; JRC Science for Policy report, 2015.

24. P. Millet, R. Ngameni, S. A. Grigoriev, N. Mbemba, F. Brisset, A. Ranjbari and C. Etiévant, Int. J. Hydrogen Energy, 2010, 35, 5043.

25. S. Siracusano, N. Hodnik, P. Jovanovic, F. Ruiz-Zepeda, M. Šala, V. Baglio and A. S. Aricò, Nano Energy, 2017, 40, 618.

26. J. Tong, Y. Liu, Q. Peng, W. Hu and Q. Wu, J. Mater. Sci., 2017, 52, 13427.

27. C. Massué, V. Pfeifer, X. Huang, J. Noack, A. Tarasov, S. Cap and R. Schlögl, ChemSusChem, 2017, 10, 1943.

28. M. J. Larsen, I. Jiménez Morales, S. Cavaliere, J. Zajac, D. J. Jones, J. Rozière, L. Kaluža, D. Gulková and M. Odgaard, Int. J. Hydrogen 
Energy, 2017, 42, 7166.

29. T. Audichon, B. Guenot, S. Baranton, M. Cretin, C. Lamy and C. Coutanceau, Appl. Catal. B Environ., 2017, $200,493$.

30. C. A. Schneider, W. S. Rasband and K. W. Eliceiri, Nat. Methods, 2012, 9, 671.

31. A. Skulimowska, M. Dupont, M. Zatoń, S. Sunde, L. Merlo, D. J. Jones and J. Rozière, Int. J. Hydrogen Energy, $2014,39,6307$.

32. M. Dou, M. Hou, F. Wang, D. Liang, Q. Zhao, Z. Shao and B. Yi, J. Electrochem. Soc., 2014, 161, F1231.

33. G. Cognard, G. Ozouf, C. Beauger, L. Dubau, M. López-Haro, M. Chatenet and F. Maillard, Electrochim. Acta, $2017,245,993$.

34. E. Fabbri, A. Rabis, R. Kötz and T. J. Schmidt, Phys. Chem. Chem. Phys., 2014, 16, 13672.

35. S. Geiger, O. Kasian, A. M. Mingers, K. J. J. Mayrhofer and S. Cherevko, Sci. Rep., 2017, 7, 3.

36. J. M. Feliu, A. Fernandez-Vega, A. Aldaz and J. Clavilier, J. Electroanal. Chem. Interfacial Electrochem., 1988, $256,149$.

37. M. Pourbaix, Atlas of Electrochemical Equilibria, Cebelcor, 1974., Cebelcor, Brussels, 1974.

38. V. Senthilkumar, P. Vickraman, M. Jayachandran and C. Sanjeeviraja, J. Mater. Sci. Mater. Electron., 2009, $21,343$.

39. Q. Liu, L. Zhang, J.-F. Chen and Y. Le, Mater. Lett., 2014, 137, 339.

40. R. Berenguer, J. M. Sieben, C. Quijada and E. Morallón, ACS Appl. Mater. Interfaces, 2014, 6, 22778.

41. C. Bernard, I. Lyon and R. Berjoan, J. SolGel Sci. Technol., 1997, 81, 75.

42. F. Montilla, E. Morallón, A. De Battisti, S. Barison, S. Daolio and J. L. Vázquez, J. Phys. Chem. B, 2004, $108,15976$.

43. K. D. Bomben, J. F. Moulder, P. E. Sobol and W. F. Stickle, Handbook of X-ray photoelectron spectroscopy: a reference book of standard spectra for identification and interpretation of XPS data, Physical Electronics, Eden Prairie, MN, 1995.

44. N. R. Elezovic, V. R. Radmilovic, J. Kovac, B. M. Babic, L. M. Gaijic-Krstajic and N. V. Krstajic, RSC Adv., 2015, 5, 15923.

45. G. Gupta, S. Sharma and P. M. Mendes, RSC Adv., 2016, 6, 82635.

46. W. E. Kleinjan, J. C. M. Brokken-Zijp, R. van de Belt, Z. Chen and G. de With, J. Mater. Res., 2011, 23, 869.

47. A. R. Babar, S. S. Shinde, A. V. Moholkar, C. H. Bhosale, J. H. Kim and K. Y. Rajpure, J. Alloys Compd., 2010, 505, 416.

48. J. Wang, G. Peng, Y. Guo and X. Yang, J. Wuhan Univ. Technol. Mater. Sci. Ed., 2008, $23,95$.

49. F. Raynal, A. Etcheberry, S. Cavaliere, V. Noël and H. Perez, Appl. Surf. Sci., 2006, 252, 2422.

50. K. Nomura, E. Kuzmann, V. K. Garg, A. C. de Oliveira, S. Stichleutner and Z. Homonnay, Hyperfine Interact., $2016,237,1$.

51. I. Savych, J. Bernard D'Arbigny, S. Subianto, S. Cavaliere, D. J. Jones and J. Rozière, J. Power Sources, 2014, $257,147$.

52. C. Marichy, G. Ercolano, G. Caputo, M. G. Willinger, D. Jones, J. Rozière, N. Pinna and S. Cavaliere, J. Mater. Chem. A, 2016, 4, 969. 